\title{
Arbor
}

\section{La pintura vista por un galerista}

\section{Lituca Peironcely}

Arbor CLXV, 649 (Enero 2000), 67-76 pp.

El Siglo XX es sin duda la época de la Historia que ha vivido más transformaciones, no sólo en lo que al Arte se refiere, sino en la Técnica, en las Ciencias, en todos los aspectos del saber humano. La generación de nuestros abuelos ha nacido en casas iluminadas con quinqués y ha llegado a la vejez asistiendo al increible espectáculo de presenciar la llegada del hombre a la luna, de contemplar en directo las montañas de Marte sentados frente a un televisor.

Desde que la electricidad llevó a los hogares hasta la clonación de genes humanos, el hombre ha sido partícipe de cambios vertiginosos que continúan asombrándole día tras día.

Partiendo de esto, como del más espectacular de los avances, el Arte y concretamente la Pintura son una manifestación clara de cualquier cambio en el pensamiento humano. En consecuencia, los pintores, los aficionados, los coleccionistas y los galeristas y en suma todos los aficionados al Arte, estamos viviendo un siglo lleno de maravillosos sobresaltos, por otro lado, consecuencias lógicas de conocimientos anteriores.

Desde la revolución que supuso el Impresionismo en su forma de entender la Pintura, hasta el Arte Conceptual y Minimalista, pasando por todos los movimientos que se han sucedido y que conviven en su diversidad, hasta nuestros días, el hombre asiste a un planteamiento radicalmente distinto viviendo una transformación de los cánones de belleza en una. riquísima búsqueda de caminos y posibilidades.

Las Galerías no sólo han ayudado a dar a conocer todos estos avances sino que hicieron posible acercar al aficionado sacando a los pintores de sus estudios y tomando parte arriesgada en esta aventura del diario descubrir. 
La sala Nadar del «Boulevard des Capucines», de París, dio, en cierto modo, en 1874 el pistoletazo de salida con una exposición que reunió a pintores como Monet, Pissarro, Renoir, Manet, Degás, Cezanne, Van Gogh, Gauguin. A este grupo, a esta manera revolucionaria de entender la pintura, la denominó - despectivamente como todos sabemos- el crítico de arte Louis Leroy, Impresionismo, por el cuadro L'lmpression de Monet. Esta corriente, que iba a ser el movimiento artístico más apasionante, formó, junto con el Surrrealismo y Abstracción, la llamada Escuela de París. Ésta, acogió a una gran parte de pintores españoles como Cossío, Picasso, Juan Gris, Vázquez Díaz, Miró, María Blanchard, Dalí, Clavé, Joaquín Peinado, Echevarría, Manuel Ángeles Ortiz, Julio González, Grau Sala, Parra, Bores, que constituyeron un grupo independiente y aún siguiendo los mismos movimientos su pintura no se confundió con la francesa ni con la de otros países, sino que conservó claramente su sabor español y fueron, decididamente, la cuna de la pintura del siglo XX español.

Algunos de ellos como Vázquez Díaz y Cossío más tarde volvieron con auras renovadoras a una España que había perdido tras la guerra civil su contacto con la pintura de Europa durante tres años y que luego siguió incomunicada otros cinco años más por la guerra mundial que siguió inmediatamente a la nuestra. Los pintores jóvenes no tenían punto de referencia; en nuestros museos era totalmente desconocido el arte vigente en Europa La moda era entonces en Madrid y en Barcelona un academicismo de raíz del XIX.. Los pintores que habían intentado una obra renovadora antes de la guerra, continuaban esa obra ante la indiferencia general. Aún así de la mano de Benjamín Palencia y Alberto Sánchez surgió la famosa Escuela de Vallecas a la que siguió la Escuela de Madrid con Diaz Caneja, Arias, Gregorio Prieto, Eduardo Vicente,Vaquero Palacios que fueron en la década de los 40 la asimilación suavizada de la versión de los principios fauvistas, picassianos, postcubistas, matissianos. Muchos proyectos renovadores no llegaron a llevarse a la práctica, limitándose todo a alguna que otra batalla aislada sostenida por Eugenio D'Ors desde las páginas de la Revista de Occidente o por Eduardo Westerdahl que fundó en Santa Cruz de Tenerife la Gaceta del Arte, dando origen al movimiento renovador del archipiélago canario, el mismo Westerdahl, se trasladi a Madrid y fundó con el doctor Blanco Soler el grupo Adland (Amigode las Artes Nuevas).

Era necesario quemar etapas, partiendo del casi total vacío y de la ausencia de interés por las nuevas modalidades que entonces cil racterizaba al público. Eugenio D’Ors vio claro que lo más important 
era educar a éste público en la comprensión del arte nuevo y para ello era imprescindible disponer de una Sala de Exposiciones que hiciera la labor educativa de acercar éstas tendencias renovadoras de los estudios del pintor a la afición de la calle. Un lugar donde estas tendencias pudieran manifestarse. Y fundó la Academia crítica del Arte, patrocinadora de los Salones de los Once que consistía en que cada uno de los miembros de la Academia elegía y patrocinaba a uno de los once mejores artistas que a lo largo del año hubiesen expuesto en Madrid y con esos once artistas se organizaba una exposición. La primera muestra se celebro en el año 43 en la Galería de Aurelio Biosca y los pintores de éste primer Salón fueron la santanderina María Blanchard, muerta en París en 1932, pero casi desconocida hasta entonces en España, los extranjeros Fujita y Olga Sacharoff y los españoles Bueno, Grau Sala, Mozos, Olasátegui, Pruna, Vicente y Zabaleta. Después de ellos se sucedieron los fundadores de la llamada Escuela de Vallecas, Benjamín Palencia y Alberto Sanchez, así como Eduardo Vicente, Solana, Zabaleta, Beulas, Cossío, Lucio Muñoz, Miró, Dalí, Esplandiú, Cullen, Chirino y un gran número más de pintores de vanguardia. Estas exposiciones de la Sala Biosca fueron definitivas en el proyecto de acercar las nuevas tendencias al público y educar la sensibilidad del aficionado que respondió con entusiasmo en un determinado sector social, la alta burguesía, que aceptó que la misión esencial de un cuadro no es imitar a la naturaleza sino ser bello en si mismo y empezó a comprar a los nuevos artistas ayudando con ello al desenvolvimiento y desarrollo de la nueva pintura en sus primeros pasos.

Paralelamente el mundo se movía lleno de propuestas. A partir de aquella "Acuarela abstracta» pintada por Kandinsky en 1910, de fondo gris casi neutro en en la que el color y la forma habían casi desaparecido del lienzo y avanzando en este camino de la simplificación Rodchenko pinta en 1918 «Negro sobre negro» y Malevich «Blanco sobre blanco", ya no se podía avanzar un paso más en el camino de la racionalización geométrica, so pena de hacer desaparecer radicalmente toda pintura, pero no por ello quedaban cerrados los caminos del arte abstracto.

El Neoplasticismo, el Futurismo, el Dadaismo entraban con fuerza. Este último surge en Suiza en 1914 como un fenómeno contra la noción misma del arte. Este movimiento tuvo su sede en el cabaret Voltaire de Zurich y el nombre se lo dio el poeta rumano Tristan Tzara, encontrando al azar en un diccionario la palabra Dadá que significa caballito de carton. De éste movimiento irónico y estrafalario dijo Tzara en un 
manifiesto: «Dadá no significa nada y nace como una necesidad de independencia y de desconfianza hacia la humanidad». Fué Peggy Guggenheim al abrir su sala de exposiciones en Londres la ayuda intelectual, artística y económica de todo aquel grupo de dadaistas, Mx Ernst, Picabia, Dalí, tanto alli como luego en su galería neoyorquina..

Este movimiento dadaísta evolucionó hacia el Surrealismo, cuya primera exposición fue en París en 1925 en la Galería Pierre de París con obras de Hans Arp, Max Ernst, Paul Klee, Picasso, Miró, Man Ray y fue mas bien un movimiento de carácter ideológico, político y literario.

Un año más tarde, abrió sus puertas la Galería Surrealista de la Rue Jacques Callot, con una exposición de Man Ray y con éste apoyo y el de las Galerías de diferentes países, el surrealismo se extendió en España a Tenerife de la mano del galerista y escritor Westerdahl, donde creció con fuerza. Y a Bélgica, donde surgió una figura clave: Renné Magritte.

En España, las corrientes dadaísmo, surrealismo, informalismo, tuvieron también su vehículo apropiado en la revista Dau al sert, revista de vanguardia con una actitud surrealista transitoria, en camino hacia el Informalismo, El nombre de Dau al Set, es decir, "dado al siete» fué sugerido por Brossa e inspirado en uno muy parecido de André Bretón «La séptima cara del dado» similar al «dos y dos hacen cinco» de Dostoiewsky. Es decir, la voluntad del irracionalismo. Sus componentes originarios fueron los pintores Cuixart, Ponc, Tápies y Tharrats, el poeta Juan Brossa, el filósofo Arnaldo Puig y el crítico y también poeta Juan Eduardo Cirlot.

Como vamos viendo los movimientos artísticos que se fueron sucediendo y conviviendo unos con otros, lo hicieron casi siempre gracias al apoyo de Galerías que creyeron en esas corrientes y que abrieron sus Salas entendiendo la necesidad de acercar al público los nuevos descubrimientos participando con ellos en la aventura del Arte. Sin la fe y el esfuerzo de éstos galeristas, algunas de éstos movimientos hubieran tardado en llegar a la calle por falta de difusión adecuada.

La pintura es un arte vivo, reflejo de los cambios de la sociedad y de la política, testigo no mudo, sino vibrante y acusador de los dolores del mundo, de la angustia de la persona. Es un grito y un testimonio vivo de cada época, es un latir caliente y comprometido. Las Galerías son el vehículo que transmite ésta sangre por las arterias de la comunicación hasta acercarlas y mezclarlas con el pueblo. Barra de unión entre el artista que pinta y el artista, que tambien lo es, 
si hacemos caso al doctor Gregorio Marañon, el que sabe mirar y siente en su interior, sin saber plasmarlo, la emoción del arte.

En España el Informalismo entraba de la mano del grupo El Paso. En él figuraron Saura, Millares, Canogar, Feito, Viola y Rivera, junto con el escultor Chirino. El grupo barcelonés tuvo sus máximos paladines en Antonio Tapies y Juan Miró, considerados por la crítica internacional como los mejores exponentes de éste movimiento cuuya raiz nutritiva es la expresividad.

El polo opuesto al de la expresividad en el panorama de la pintura abstracta en España es el de la abstracción analítica y formal y en ella destacaron Pablo Palazuelo, José María Labra, Sempere.

Numerosos grupos fueron apareciendo en España como: Equipo 57, Equipo Realidad, Equipo Espacio, todos ellos dentro del grupo Córdoba, que se constituyó con un fondo de consignas de búsqueda espacial metafísica aportadas por Jorge Oteyza.

El Equipo Crónica como exponente del Arte Pop: arte popular, arte de la calle, de la calle de una sociedad consumista, la publicidad, los colores planos, los espacios fríos.

En Nueva York el Informalismo fue impulsado por dos Galerías, la de Julien Lèvy y la de la famosa Peggy Guggenheim, que se trasladó de la de Londres y abrió otra galería situada en la calle 57, diseñada por el arquitecto Kiesler y que describe la propia Peggy con éstas palabras: (1) «Los cuadros estaban montados sobre bates de béisbol y las luces se encendían y apagaban cada tres segundos, iluminando primero una parte de la Galería y luego otra... las dos paredes, las formaban una cortina de color azul, asemejando a la carpa de un circo y en el centro de la habitación, los cuadros se arracimaban componiendo triángulos colgados de cuerdas como si flotaran por el espacio»...

Peggy se casó con Max Ernst, del que se divorció poco después, aunque él siguió exponiendo en su galería junto con los amigos de ambos, Picasso, Miró, Man Ray, Calder, Hans Arp. La Galería fue además punto de reunión y apoyo a escritores e intelectuales como Samuel Beckett, Jean Cocteau, Marcel Duchamp.y logró impulsar a muchos artistas, por entonces desconocidos, como Motherwell, Rothko, Pollock, o de Kooning, que inauguraron la galería con una de las primeras muestras de Arte Abstracto Expresionista titulada «The Art of this Century» Gracias al apoyo, la protección y el entusiasmo de esta arrolladora galerista de gran intuición artística, este movimiento provocó una rápida reacción de entusiasmo colectivo entre el público. 
Tambien el MOMA, con la exposición «Expresionismo Abstracto» consolidó la Escuela de Nueva York.

Y la Galería Whitney, que primero fue academia-estudio abierto a todas las tendencias «con tal que fueran sinceras» y más tarde fue sala de exposiciones al final se convirtió en Museo al albergar la extensa colección de pintura que Mrs. Whitney ofreció al Metropolitan Museum of Art y que éste rechazó. Con lo que en 1928 se abrieron las puertas del nuevo Whitney Museum of American Art, que hoy día junto con el MOMA y el Guggenheim son las tres catedrales que alentaron, conservaron y acercaron la pintura y los diferentes cambios, al aficionado $\mathrm{y}$ al mundo en general.

Una de las primeras galerías que promovió a los artistas neoyorquinos del Pop Art fué la Galería Reuben del centro de Nueva York, que luego se trasladó como otras galerías y pintores Pop a los «barrios bajos».

La Galería Reuben organizó happenings y exposiciones promoviendo la participación del público en el proceso de la creación eliminando las fronteras entre el objeto y el espectador al igual que hicieron la Galería de Leo Castelli y la de Martha Jackson.

El Pop americano nos llenó de latas de sopa Campbell con Andy Warhol, Lichtenstein y sus comics de puntos negros. Jasper Jhones y sus banderas. Ironía, sentido del humor, desmitificar la transcendencia del arte, acercarlo. El Pop Artt es un arte conceptual. Los cuadros se convierten en cosas y las cosas se convierten en cuadros.

Como reacción al Pop surgió el minimalismo término usado por Wollheim para referirse a los productos artísticos que más se alejaban de la pintura y escultura tradicionales, y que se aplicó a ésta corriente artística surgida en Estados Unidos. Son obras de estructuras primarias creando formas visuales reducidas al mínimo. Estas obras carecen de cualquier tipo de mensaje o argumento.

$\mathrm{Su}$ elaboración material, a base de productos ya existentes como un tubo de neón o materiales industriales o domésticos, no suele correr a cargo del artista que ejecuta solo el boceto dejando la realización de la obra a firmas industriales. Los primeros artistas de éste movimiento fueron Sol Lewit y Robert Morris. Tendencia muy próxima a ésta es el Arte povera, arte pobre, en el que se utilizan, no productos industriales sino los considerados como pobres y en muchos casos perecederos, como hierba, hielo, arena y en algunos casos vapor, como en la exposición reciente en el Museo de Miró de Barcelona, lo cual hace aún más difícil su conservación en manos particulares. Seguidores suyos son Joseph Beuys, Mrio Merz, Eva Hess. Es también conocido 
La pintura vista por un galerista

FIGURA 1. «Sopa Campeells» Andy Warhol

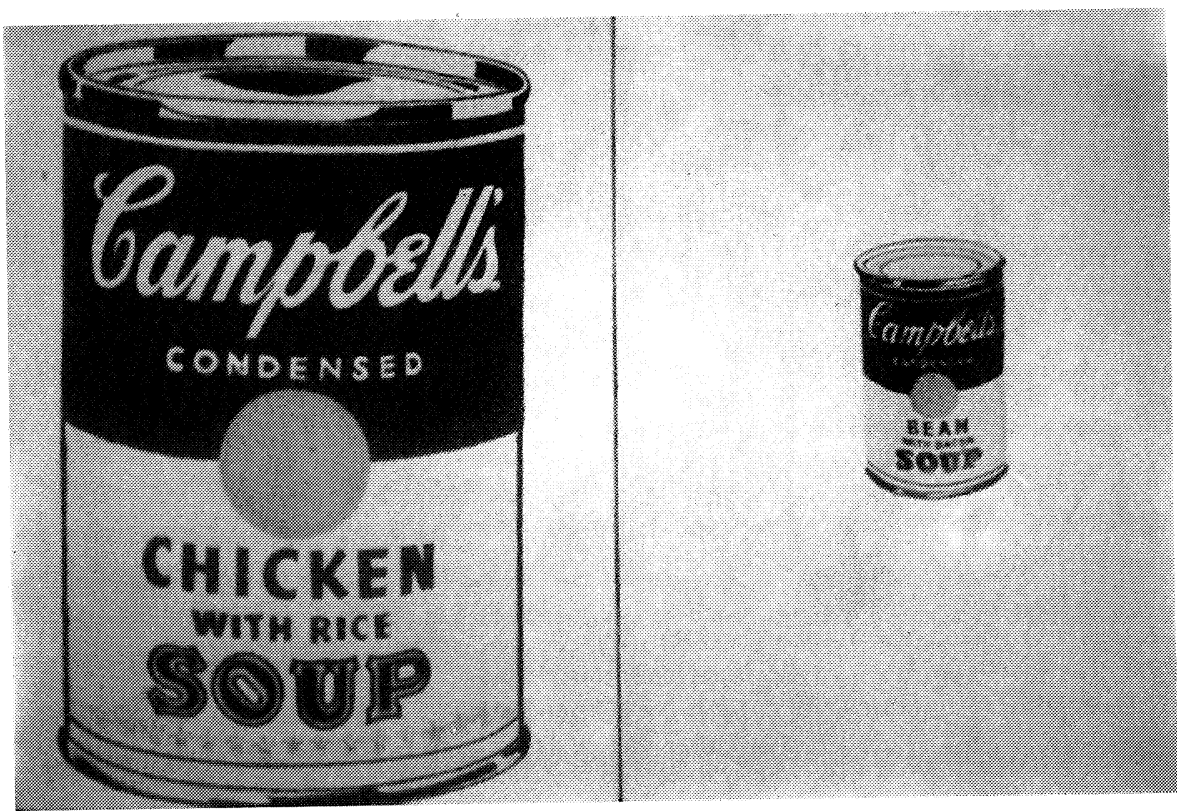

FigurA 2. «The flag start» Jasper Jons

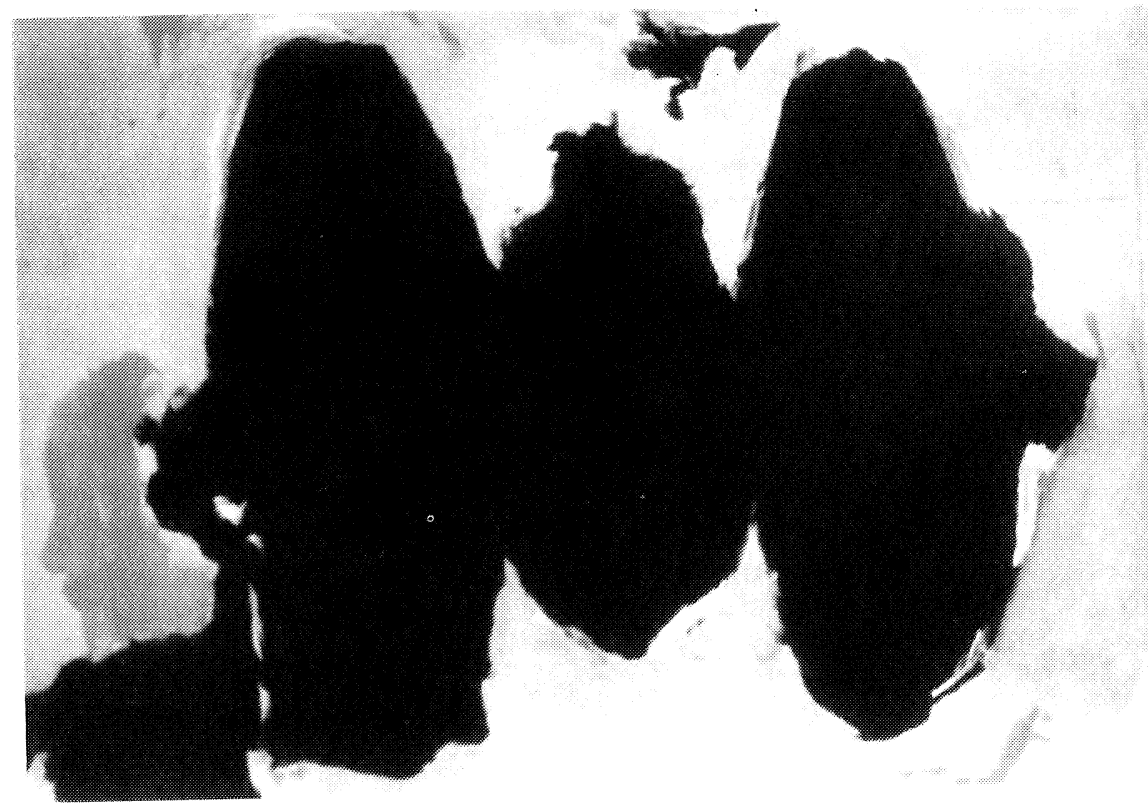




\section{Lituca Peironcely}

74

FigurA 3. «Catalan elegy» Robert Motherwell

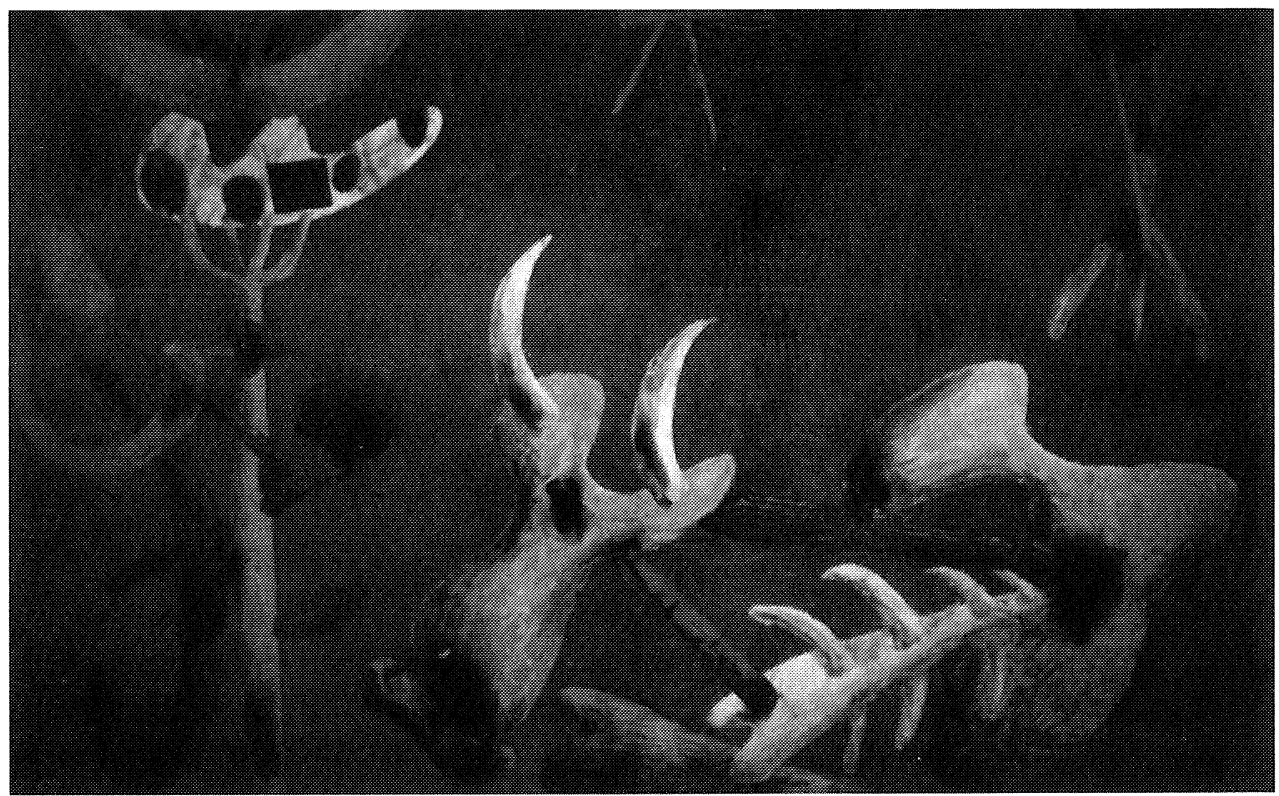

FIGURA 4. «Paisaje 1934» Benjamin Palencia






\section{La pintura vista por un galerista}

FIGURA 5. «Estudio» Equipo Crónica

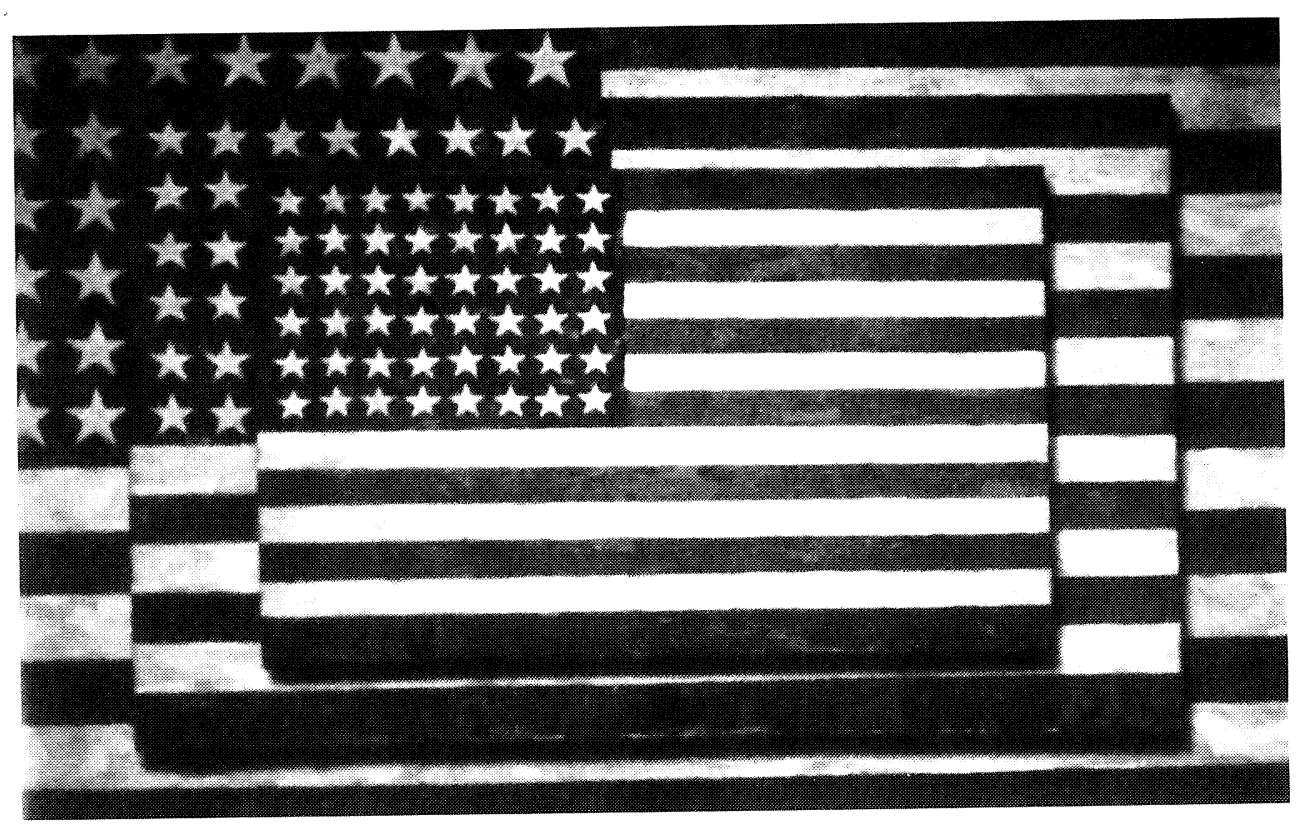

como Process Art o Arte procesual. El arte ha traspasado ya los límites de las Galerías. No sólo está ya en la calle, sino que materialmente ya no cabe en pequeños recintos.

Con el arte conceptual el oficio de las galerías se divide y dispersa. Hoy día hay infinidad de salas de exposiciones y el aficionado elige lo que más le gusta, mira, aprende, se pone al día en una palabra, de todas las corrientes y novedades no sólo en las galerías ni a través de los numerosos medios de comunicación, sino muy principalmente ahora también en los museos.

Los museos han empezado a perder el sentido tradicional de algo muerto para incorporarse directamente a la vida creando espacios expositivos que admitan ésas nuevas manifestaciones artísticas que como el arte conceptual, el Minimal Art ABC-Art, necesitan un mayor espacio del que puede ofrecer una sala y donde además puedan hacerse depositarios como Museos, de las muestras de estas nuevas tendencias para dar en el futuro constancia de ellas, ya que por sus características, son difíciles a veces de exponer en ciertas galerías e incluso de guardar y coleccionar por el aficionado.

En España, el Reina Sofía en Madrid, el Guggenheim en Bilbao, el museo de Miró en Barcelona, La Caixa en Barcelona y Madrid, el 


\section{Lituca Peironcely}

76

recién estrenado Museo de Arte Contemporáneo de Segovia, son muestra del relevo que las grandes instituciones han tomado de lo que durante muchos y muy cruciales años fue el papel de las Galerías que a su vez, en algunos casos, como hemos visto se transformaron de Salas de Exposiciones comerciales en Museos subvencionados por Bancos u otras entidades.

\section{Bibliografía}

Carmen Rocamora: "Ismos y Vanguardias del siglo XX".

José María MoReno GaLváN: «Introducción a la pintura española actual».

Francisco Calvo Serraller: «Naturaleza española. Naturaleza y naturalismo en el arte español».

Carlos Antonio AREÁN: "Veinte años de pintura de vanguardia en España».

Barbara Haskell: «The American Century».

Tilman Osterwold: «Pop Art». 